\title{
The EPHX1 rs1051740 Polymorphism Is Associated with Childhood Acute Lymphoblastic Leukemia in a Korean Population
}

\author{
Hee Nam Kim¹, Nan Young Kim², Li Yu², Il-Kwon Lee², Min-Ho Shin',3, Hee Jo Baek ${ }^{2,4}$, \\ Hoon Kook ${ }^{2,4}$, Hyeoung-Joon Kim ${ }^{2,5 *}$ \\ ${ }^{1}$ Center for Creative Biomedical Scientists, Chonnam National University, Gwangju, Korea \\ ${ }^{2}$ Environmental Health Center for Childhood Leukemia and Cancer, Chonnam National University Hwasun \\ Hospital, Hwasun, Korea \\ ${ }^{3}$ Department of Preventive Medicine, Chonnam National University Medical School, Gwangju, Korea \\ ${ }^{4}$ Department of Pediatrics, Chonnam National University Medical School, Hwasun, Korea \\ ${ }^{5}$ Department of Hematology/Oncology, Chonnam National University Hwasun Hospital, Hwasun, Korea \\ Email: ${ }^{\text {hjoonk@chonnam.ac.kr }}$
}

Received 22 April 2014; revised 31 May 2014; accepted 18 June 2014

Copyright (C) 2014 by authors and Scientific Research Publishing Inc.

This work is licensed under the Creative Commons Attribution International License (CC BY).

http://creativecommons.org/licenses/by/4.0/

cc) (i) Open Access

\begin{abstract}
Microsomal epoxide hydrolase (EPHX1) is involved in the activation and detoxification of exogenous chemicals. Genetic polymorphisms in EPHX1 have been associated with the development of leukemia. To investigate an association between single-nucleotide polymorphisms (SNPs) of EPHX1 and risk factors for childhood acute lymphoblastic leukemia (ALL) in Korean children, we genotyped two SNPs, Tyr113His (rs1051740) and His139Arg (rs2234922) in 185 childhood ALL cases and 536 healthy controls. Genotyping for these two SNPs was performed by simplex pyrosequencing assay and high-resolution melt analysis, respectively. We found that the Tyr113His genotype was associated with a decreased risk of childhood ALL (odds ratio, $0 \mathrm{R}=0.64,95 \%$ confidence interval, $\mathrm{CI}=0.43-0.93 ; p=0.02$ ). There was no association between His139Arg and the combined genotypes and the risk of childhood ALL. These results suggest that the EPHX1 113TyrHis genotype may protect against leukemogenesis in childhood.
\end{abstract}

\section{Keywords}

EPHX1, Polymorphism, Association, Childhood ALL

${ }^{*}$ Corresponding author.

How to cite this paper: Kim, H.N., et al. (2014) The EPHX1 rs1051740 Polymorphism Is Associated with Childhood Acute Lymphoblastic Leukemia in a Korean Population. Advances in Bioscience and Biotechnology, 5, 678-684. 


\section{Introduction}

Childhood acute lymphoblastic leukemia (ALL) is the most common type of cancer in children, representing nearly one-third of all pediatric cancers [1]. Childhood ALL is caused by multiple factors, including genetic disorders, exposure to radiation, and immune dysfunction [2] [3]. Environmental factors, such as pesticides, household chemical exposure, and parental smoking and alcohol use, have also been associated with childhood cancers, including childhood ALL [3]-[5]. These factors are detoxified by drug-metabolizing enzymes, through phase I and II metabolism.

Many studies have suggested that genetic polymorphisms in the drug-metabolizing enzymes play a role in susceptibility to childhood ALL [6]-[9]. Recent studies have suggested that the interaction between these genes and environmental factors may also affect the susceptibility to leukemia [10]-[12]. Microsomal epoxide hydrolase (EPHX1), along with CYP, another family of xenobiotic-metabolizing enzymes, plays an important role in both the detoxification and activation of procarcinogens [13] [14] and is considered to be a protective enzyme [15]. Two polymorphisms in EPHX1, Tyr113 His in exon 3 (rs1051740) and His139Arg in exon 4 (rs2234922), have been identified to affect enzyme activity. The 113His allele in exon 3 decreases enzyme activity by $40 \%$ and is called the "slow" allele, whereas the 139Arg allele in exon 4 increases enzyme activity in vitro by $25 \%$ and is referred to as the "fast" allele [16].

Previous studies have reported inconsistent findings regarding an association between EPHX1 polymorphisms and cancer risk [17]-[20]. To our knowledge, only three reported studies have analyzed these polymorphisms in childhood ALL [7] [11] [21], with the results being variable. Additionally, no research on an Asian population has been published. Thus, the aim of this study was to investigate the association of these two polymorphisms and their haplotypes in EPHX1 with the risk of childhood ALL in Korean children.

\section{Materials and Methods}

\subsection{Study Population}

All childhood ALL less than 18 years of age were consecutively enrolled at Chonnam National University Hwasun Hospital between October 2001 and August 2012. The 185 ALL cases consisted of 105 males and 80 females, with a mean age of $6.2 \pm 4.2$ years (range, 3 months to 17 years).

The control group consisted of 536 unrelated individuals (267 males, 269 females) with a mean age of $7.5 \pm$ 4.0 years (range, 1 month to 17 years) with no previous history of malignancy. The controls were selected randomly from local residents during the same time period.

At the time of peripheral blood collection, the parents of all cases and control subjects provided informed consent to participate in this study. Childhood ALL cases for this study were provided by the Chonnam National University Hwasun Hospital National Biobank of Korea, a member of the National Biobank of Korea, supported by the Ministry of Health, Welfare, and Family Affairs. This study was approved by the Chonnam National University Hwasun Hospital Institutional Review Board, Hwasun, Korea.

\subsection{Genotyping}

Genomic DNA was extracted from peripheral blood using a QIAamp DNA Blood Mini Kit (Qiagen, Valencia, CA), according to the manufacturer's protocol. Genotyping for the Tyr113His polymorphism was performed by a simplex pyrosequencing assay as described previously (Figure 1) [22]. The specific primers designed using the Pyrosequencing SNP primer design software (ver. 1.0.6) were as follows: F: 5'-ACTGGAAGAAGCAGGTGGAGATT-3' and R: 5'-ACTGGAAGAAGCAGGTGGAGATT-3'. PCR was performed in a $20 \mu \mathrm{L}$ reaction volume containing $200 \mathrm{nM}$ PCR primer, $0.5 \mathrm{U}$ f-Taq polymerase (Solgent, Daejeon, Korea), and 40 ng of genomic DNA. The cycling conditions were started with denaturation at $95^{\circ} \mathrm{C}$ for 5 min, followed by 35 cycles of $94^{\circ} \mathrm{C}$ for $20 \mathrm{~s}, 62^{\circ} \mathrm{C}$ for $30 \mathrm{~s}$ and $72^{\circ} \mathrm{C}$ for $30 \mathrm{~s}$. Genotyping for His139Arg was performed by high-resolution melt analysis (HRM), as described previously (Figure 2) [23]. The primer pair for this polymorphism was F: 5'-GGCTGGACATCCACTTCATC-3' and R: 5'-GTTCTTGGGGTCAGTCAGGA-3'. The reaction mixture for HRM included 200 nM PCR primer, $1 \mu \mathrm{M}$ SYTO 9 fluorescent dye (Invitrogen, Carlsbad, CA, USA), 0.5 U f-Taq polymerase (Solgent, Daejeon, Korea), and 40 ng of genomic DNA in $10 \mu \mathrm{L}$ reaction volumes. The cycling conditions included an initial 5-min hold at $95^{\circ} \mathrm{C}$, followed by 40 cycles at $94^{\circ} \mathrm{C}$ for $30 \mathrm{~s}, 62^{\circ} \mathrm{C}$ for $30 \mathrm{~s}$, and $72^{\circ} \mathrm{C}$ for $30 \mathrm{~s}$ and melting increasing from $85^{\circ} \mathrm{C}$ to $91^{\circ} \mathrm{C}$ at $0.1^{\circ} \mathrm{C}$ per second. 

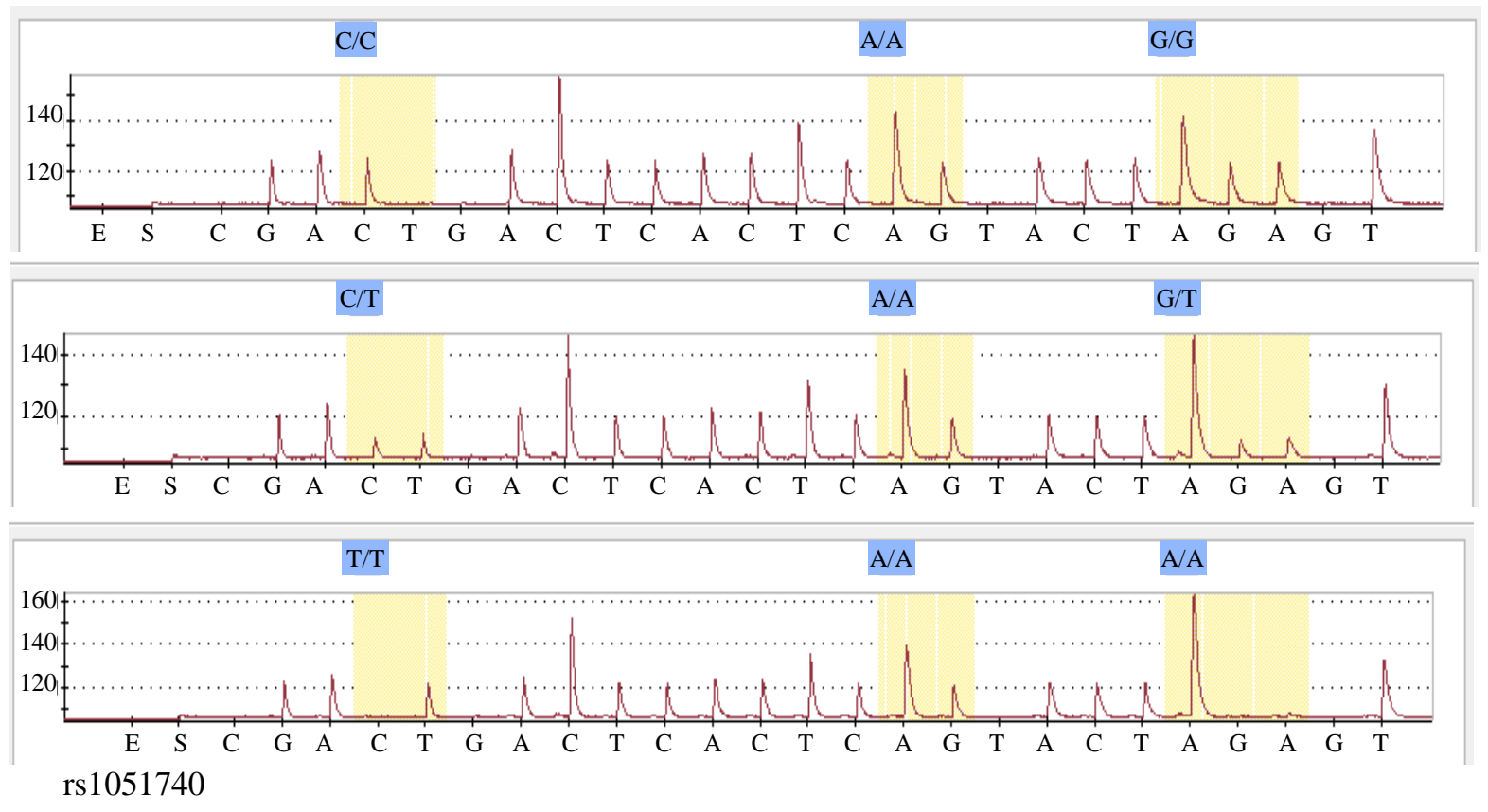

Figure 1. Typical pyrosequencing results for Tyr113His polymorphism. Upper: CC homozygotes; Middle: CT heterozygotes; Bottom: TT homozygotes.

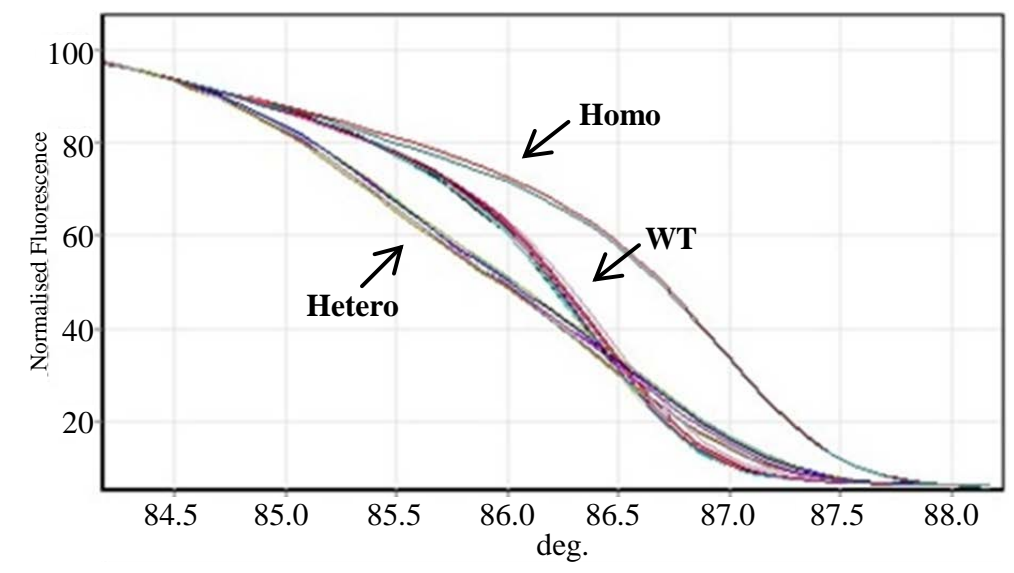

Figure 2. Typical HRM results for His139Arg polymorphism. WT: AA homozygotes; Hetero: AG heterozygotes; Homo: GG homozygotes.

\subsection{Statistical Analysis}

The expected frequency of control genotypes was evaluated using the Hardy-Weinberg equilibrium test. Adjusted odds ratios (ORs) and 95\% confidence intervals (CIs) were calculated using logistic regression models, adjusting for age and gender, to estimate the association between each genotype and childhood ALL. Subjects with wild-type genotypes were considered to represent the baseline risk. Statistical analyses were performed using the SPSS software version 21.0 (SPSS, Inc., an IBM Company, Chicago, IL, USA).

\section{Results}

The distributions of polymorphisms in EPHX1 among the childhood ALL cases and the controls are shown in Table 1. Two major polymorphisms, Tyr113His in exon 3 and His139Arg in exon 4, were analyzed. The control genotype frequencies were within Hardy-Weinberg equilibrium and did not differ significantly between males and females (data not shown). EPHX1 113Tyr/His and the combined Tyr/His and His/His genotypes were asso- 
ciated with a decreased risk for childhood ALL $\left(\mathrm{OR}_{\mathrm{TC}}=0.64, p=0.02\right.$; $\left.\mathrm{OR}_{\mathrm{TC}+\mathrm{CC}}=0.68, p=0.03\right)$. No association was found between the His139Arg polymorphism and the risk of childhood ALL.

The distribution of the combined genotypes of EPHX1 Tyr113His and His139Arg polymorphisms with the imputed phenotypes [16] between the cases and controls are shown in Table 2. Eight genotype combinations, the exceptions being $113 \mathrm{His} / \mathrm{His}$ and 139Arg/Arg, are listed. No association was found between the combined genotypes with imputed phenotypes and the risk of childhood ALL compared with normal EPHX1 enzyme activity.

\section{Discussion}

In the present study, we investigated whether two polymorphisms in EPHX1 genes were associated with a risk of developing childhood ALL in a Korean population. The Tyr113His genotype was associated with a decreased risk of childhood ALL. There was no association between the His139Arg polymorphism and the combined genotypes and the risk of childhood ALL.

$E P H X 1$ is an important metabolizing enzyme that is involved in detoxification by catalyzing the hydrolysis of arene and aliphatic epoxides from PAHs and activation by generating carcinogenic compounds from epoxides [13] [14]. Two major polymorphisms, the 113 His allele in exon 3 (rs1051740) and the 139 Arg allele in exon 4

Table 1. Association between polymorphisms in EPHX1 and risk of childhood ALL.

\begin{tabular}{|c|c|c|c|c|c|}
\hline SNP & Genotype & Control, $n(\%)$ & Case, $n(\%)$ & OR $(95 \% \mathrm{CI})$ & $p$ \\
\hline EPHX1 & $\mathrm{T} / \mathrm{T}$ & $156(29.1)$ & $71(38.4)$ & 1 & \\
\hline Y113H & $\mathrm{T} / \mathrm{C}$ & 277 (51.7) & $78(42.2)$ & $0.64(0.43-0.93)$ & 0.02 \\
\hline \multirow[t]{4}{*}{ rs1051740 } & $\mathrm{C} / \mathrm{C}$ & $103(19.2)$ & 36 (19.5) & $0.79(0.49-1.27)$ & 0.32 \\
\hline & $\mathrm{T} / \mathrm{C}-\mathrm{C} / \mathrm{C}$ & 380 (70.9) & $114(61.6)$ & $0.68(0.48-0.96)$ & 0.03 \\
\hline & $\mathrm{T}$ allele & 589 (54.9) & $220(59.5)$ & 1 & \\
\hline & $\mathrm{C}$ allele & $483(45.1)$ & $150(40.5)$ & $0.84(0.66-1.07)$ & 0.17 \\
\hline$E P H X 1$ & $\mathrm{~A} / \mathrm{A}$ & $399(74.4)$ & 125 (67.6) & 1 & \\
\hline H139R & $\mathrm{A} / \mathrm{G}$ & 123 (22.9) & $56(30.3)$ & $1.43(0.98-2.09)$ & 0.07 \\
\hline \multirow[t]{4}{*}{ rs2234922 } & $\mathrm{G} / \mathrm{G}$ & $14(2.6)$ & $4(2.2)$ & $0.90(0.29-2.81)$ & 0.85 \\
\hline & A/G-G/G & $137(25.6)$ & $60(32.4)$ & $1.37(0.95$ - 1.99) & 0.09 \\
\hline & A allele & 921 (85.9) & 306 (82.7) & 1 & \\
\hline & G allele & $151(14.1)$ & 64 (17.3) & $1.26(0.91-1.74)$ & 0.17 \\
\hline
\end{tabular}

Table 2. Association between the combined EPHX1 Tyr113His and His139Arg polymorphism genotypes and risk of childhood ALL.

\begin{tabular}{|c|c|c|c|c|c|}
\hline Genotype & Imputed phenotype & Control, $n(\%)$ & Case, $n(\%)$ & OR (95\% CI) & $p$ \\
\hline 113Tyr/Tyr and 139His/His & Normal & $110(20.5)$ & $43(23.2)$ & 1 & \\
\hline 113Tyr/His and 139His/Arg & Normal & $75(14.0)$ & $22(11.9)$ & $0.76(0.42-1.37)$ & 0.36 \\
\hline 113Tyr/Tyr and 139His/Arg & Fast & $37(6.9)$ & $26(14.1)$ & $1.79(0.96-3.23)$ & 0.07 \\
\hline 113Tyr/Tyr and 139Arg/Arg & Fast & $9(1.7)$ & $2(1.1)$ & $0.54(0.11-2.65)$ & 0.45 \\
\hline 113Tyr/His and 139His/His & Slow & $197(36.8)$ & $54(29.2)$ & $0.72(0.45-1.15)$ & 0.17 \\
\hline 113Tyr/His and 139Arg/Arg & Slow & $5(0.9)$ & $2(1.1)$ & $1.11(0.20-6.07)$ & 0.90 \\
\hline 113His/His and 139His/His & Very slow & $92(17.2)$ & $28(15.1)$ & $0.80(0.46-1.39)$ & 0.43 \\
\hline 113His/His and 139His/Arg & Very slow & $8(1.5)$ & $19(10.3)$ & $1.84(0.69-4.96)$ & 0.23 \\
\hline
\end{tabular}


(rs2234922), are known to reduce and increase enzyme activity, respectively [16]. To date, these two polymorphisms were considered to be associated with cancer risk. However, the many studies that have investigated this have produced inconsistent findings. The Tyr113His polymorphism has been associated with, in most studies, an increased risk for various cancers, such as lung [20] [24] [25], ovarian [26], esophageal [27], breast [28], and bladder [29] cancer and, in a few studies, a decreased risk of childhood ALL [7] and lung cancer [30]. In contrast, the His139Arg polymorphism has no association with many cancers [11] [27] [29] [31]. These results suggest that the decreased enzyme activity of the His allele in the Tyr113His polymorphism affects the risk of cancer to a greater degree than the increased enzyme activity due to the Tyr allele in the Tyr113His polymorphism.

In the present study, the 113Tyr/His and the combined Tyr/His and His/His genotypes were associated with a decreased risk of childhood ALL, while the His139Arg polymorphism had no effect. Three studies of childhood ALL risk have also reported no association with His139Arg, while Tyr113His showed a decreased risk [7] in Brazil, an increase [21] in Turkey, and no association [11] in France. Our results are similar to those of Silveira Vda et al. [7].

The conflicting results for the associations between the polymorphisms and the risk for ALL may be due to differing genotype frequencies, ethnicities, and environmental factors. In the four studies, including ours, the frequencies of the $113 \mathrm{His} / \mathrm{His}$ genotype in the control groups ranged from $2 \%$ to $18.4 \%$. However, the frequencies of the $139 \mathrm{Arg} / \mathrm{Arg}$ genotype in the control groups were less diverse, ranging from $2.1 \%$ to $4.4 \%$.

Correlations between EPHX1 enzymatic activity and different combinations of the two variants were reported by Hasset et al. [16], and activity was suggested to be a cancer risk factor. Tumer et al. reported that only the very low activity of the $113 \mathrm{His} / \mathrm{His}$ and $139 \mathrm{His} / \mathrm{His}$ combinations significantly increased the risk of childhood ALL [21]. However, in our study, no associations were found between these combinations and childhood ALL.

Our study had several limitations. First, we did not evaluate gene-environment interactions. Zhou et al. reported that lung cancer risk decreased as cumulative smoking increased and suggested that smoking plays an important role in the association of the His/His genotype with lung cancer [32]. Several studies have suggested that the interaction between drug-metabolizing genes and parental smoking and alcohol might affect childhood leukemia [11] [12] [33]. Thus, additional studies with stratification according to chemical exposure and with larger sample sizes in local areas should be conducted to further explore the associations between EPHX1 polymorphisms and childhood leukemogenesis. Second, it is possible that the null association between His139Arg and childhood ALL may have been due to the small sample size.

\section{Conclusion}

In conclusion, the EPHX1 $113 \mathrm{Arg} / \mathrm{His}$ genotype was associated with a decreased risk of childhood ALL in Korean children. These results suggest that Arg113His polymorphism may have some protective function against leukemogenesis in childhood.

\section{Acknowledgements}

This study was supported by a grant from Environmental Health Center for Childhood Leukemia and Cancer.

\section{Declaration of Interest}

The authors declare that they have no competing interests.

\section{References}

[1] Linet, M.S., Ries, L.A., Smith, M.A., Tarone, R.E. and Devesa, S.S. (1999) Cancer Surveillance Series: Recent Trends in Childhood Cancer Incidence and Mortality in the United States. Journal of the National Cancer Institute, 91, 1051-1058. http://dx.doi.org/10.1093/jnci/91.12.1051

[2] Shannon, K. (1998) Genetic Predispositions and Childhood Cancer. Environmental Health Perspectives, 106, $801-806$. http://dx.doi.org/10.1289/ehp.98106801

[3] Olshan, A.F. and van Wijngaarden, E. (2003) Paternal Occupation and Childhood Cancer. Advances in Experimental Medicine and Biology, 518, 147-161. http://dx.doi.org/10.1007/978-1-4419-9190-4_12

[4] Carozza, S.E., Li, B., Wang, Q., Horel, S. and Cooper, S. (2009) Agricultural Pesticides and Risk of Childhood Can- 
cers. International Journal of Hygiene and Environmental Health, 212, 186-195. http://dx.doi.org/10.1016/j.ijheh.2008.06.002

[5] Vinson, F., Merhi, M., Baldi, I., Raynal, H. and Gamet-Payrastre, L. (2011) Exposure to Pesticides and Risk of Childhood Cancer: A Meta-Analysis of Recent Epidemiological Studies. Occupational and Environmental Medicine, 68, 694-702. http://dx.doi.org/10.1136/oemed-2011-100082

[6] Krajinovic, M., Labuda, D., Richer, C., Karimi, S. and Sinnett, D. (1999) Susceptibility to Childhood Acute Lymphoblastic Leukemia: Influence of CYP1A1, CYP2D6, GSTM1, and GSTT1 Genetic Polymorphisms. Blood, 93, 1496-1501.

[7] Silveira Vda, S., Canalle, R., Scrideli, C.A., Queiroz, R.G. and Tone, L.G. (2010) Role of the CYP2D6, EPHX1, MPO, and NQO1 Genes in the Susceptibility to Acute Lymphoblastic Leukemia in Brazilian Children. Environmental and Molecular Mutagenesis, 51, 48-56. http://dx.doi.org/10.1002/em.20510

[8] Tang, Q., Li, J., Zhang, S., Yuan, B., Sun, H., Wu, D., et al. (2013) GSTM1 and GSTT1 Null Polymorphisms and Childhood Acute Leukemia Risk: Evidence from 26 Case-Control Studies. PloS One, 8, Article ID: e78810. http://dx.doi.org/10.1371/journal.pone.0078810

[9] Xu, L.Y. and Cao, L.F. (2014) GSTT1 Genetic Polymorphism and Susceptibility to Childhood Acute Lymphoblastic Leukemia: A Meta-Analysis. Tumour Biology, 35, 1433-1437. http://dx.doi.org/10.1007/s13277-013-1197-X

[10] Bonaventure, A., Goujon-Bellec, S., Rudant, J., Orsi, L., Leverger, G., Baruchel, A., et al. (2012) Maternal Smoking during Pregnancy, Genetic Polymorphisms of Metabolic Enzymes, and Childhood Acute Leukemia: The ESCALE Study (SFCE). Cancer Causes \& Control: CCC, 23, 329-345. http://dx.doi.org/10.1007/s10552-011-9882-9

[11] Clavel, J., Bellec, S., Rebouissou, S., Menegaux, F., Feunteun, J., Bonaiti-Pellie, C., et al. (2005) Childhood Leukaemia, Polymorphisms of Metabolism Enzyme Genes, and Interactions with Maternal Tobacco, Coffee and Alcohol Consumption during Pregnancy. European Journal of Cancer Prevention, 14, 531-540. http://dx.doi.org/10.1097/00008469-200512000-00007

[12] Yang, Y., Tian, Y., Jin, X., Yan, C., Jiang, F., Zhang, Y., et al. (2009) A Case-Only Study of Interactions between Metabolic Enzyme Polymorphisms and Industrial Pollution in Childhood Acute Leukemia. Environmental Toxicology and Pharmacology, 28, 161-166. http://dx.doi.org/10.1016/j.etap.2009.03.004

[13] Miyata, M., Kudo, G., Lee, Y.H., Yang, T.J., Gelboin, H.V., Fernandez-Salguero, P., et al. (1999) Targeted Disruption of the Microsomal Epoxide Hydrolase Gene. Microsomal Epoxide Hydrolase Is Required for the Carcinogenic Activity of 7,12-Dimethylbenz[a]Anthracene. The Journal of Biological Chemistry, 274, 23963-23968. http://dx.doi.org/10.1074/jbc.274.34.23963

[14] Omiecinski, C.J., Hassett, C. and Hosagrahara, V. (2000) Epoxide Hydrolase-Polymorphism and Role in Toxicology. Toxicology Letters, 112-113, 365-370. http://dx.doi.org/10.1016/S0378-4274(99)00235-0

[15] Vodicka, P., Soucek, P., Tates, A.D., Dusinska, M., Sarmanova, J., Zamecnikova, M., et al. (2001) Association between Genetic Polymorphisms and Biomarkers in Styrene-Exposed Workers. Mutation Research, 482, 89-103. http://dx.doi.org/10.1016/S0027-5107(01)00214-7

[16] Hassett, C., Aicher, L., Sidhu, J.S. and Omiecinski, C.J. (1994) Human Microsomal Epoxide Hydrolase: Genetic Polymorphism and Functional Expression in Vitro of Amino Acid Variants. Human Molecular Genetics, 3, 421-428. http://dx.doi.org/10.1093/hmg/3.3.421

[17] Ghoshal, U., Kumar, S., Jaiswal, V., Tripathi, S., Mittal, B. and Ghoshal, U.C. (2013) Association of Microsomal Epoxide Hydrolase Exon 3 Tyr113His and Exon 4 His139Arg Polymorphisms with Gastric Cancer in India. Indian Journal of Gastroenterology, 32, 246-252. http://dx.doi.org/10.1007/s12664-013-0332-3

[18] Chauhan, P.S., Ihsan, R., Yadav, D.S., Mishra, A.K., Bhushan, B., Soni, A., et al. (2011) Association of Glutathione S-Transferase, EPHX, and p53 Codon 72 Gene Polymorphisms with Adult Acute Myeloid Leukemia. DNA and Cell Biology, 30, 39-46. http://dx.doi.org/10.1089/dna.2010.1092

[19] Conesa-Zamora, P., Ruiz-Cosano, J., Torres-Moreno, D., Espanol, I., Gutierrez-Meca, M.D., Trujillo-Santos, J., et al. (2013) Polymorphisms in Xenobiotic Metabolizing Genes (EPHX1, NQO1 and PON1) in Lymphoma Susceptibility: A Case Control Study. BMC Cancer, 13, 228. http://dx.doi.org/10.1186/1471-2407-13-228

[20] Wang, S., Zhu, J., Zhang, R., Wang, S. and Gu, Z. (2013) Association between Microsomal Epoxide Hydrolase 1 T113C Polymorphism and Susceptibility to Lung Cancer. Tumour Biology, 34, 1045-1052. http://dx.doi.org/10.1007/s13277-012-0644-4

[21] Tumer, T.B., Sahin, G. and Arinc, E. (2012) Association between Polymorphisms of EPHX1 and XRCC1 Genes and the Risk of Childhood Acute Lymphoblastic Leukemia. Archives of Toxicology, 86, 431-439. http://dx.doi.org/10.1007/s00204-011-0760-8 
[22] Kim, H.N., Lee, I.K., Kim, Y.K., Tran, H.T., Yang, D.H., Lee, J.J., et al. (2008) Association between Folate-Metabolizing Pathway Polymorphism and Non-Hodgkin Lymphoma. British Journal of Haematology, 140, 287-294. http://dx.doi.org/10.1111/j.1365-2141.2007.06893.xhttp://dx.doi.org/10.1111/j.1365-2141.2007.06893.X

[23] Kim, H.N., Kim, N.Y., Yu, L., Kim, Y.K., Lee, I.K., Yang, D.H., et al. (2009) Polymorphisms of Drug-Metabolizing Genes and Risk of Non-Hodgkin Lymphoma. American Journal of Hematology, 84, 821-825. http://dx.doi.org/10.1002/ajh.21556

[24] Erkisi, Z., Yaylim-Eraltan, I., Turna, A., Gormus, U., Camlica, H. and Isbir, T. (2010) Polymorphisms in the Microsomal Epoxide Hydrolase Gene: Role in Lung Cancer Susceptibility and Prognosis. Tumori, 96, 756-763.

[25] Tilak, A.R., Kumar, S., Jain, M., Pant, M.C., Das, B.C., Guleria, R., et al. (2011) Association of Functionally Important Polymorphism of Microsomal Epoxide Hydrolase Gene (EPHX1) with Lung Cancer Susceptibility. Cancer Investigation, 29, 411-418. http://dx.doi.org/10.3109/07357907.2011.587070

[26] Goode, E.L., White, K.L., Vierkant, R.A., Phelan, C.M., Cunningham, J.M., Schildkraut, J.M., et al. (2011) Xenobiotic-Metabolizing Gene Polymorphisms and Ovarian Cancer Risk. Molecular Carcinogenesis, 50, 397-402. http://dx.doi.org/10.1002/mc.20714

[27] Jain, M., Tilak, A.R., Upadhyay, R., Kumar, A. and Mittal, B. (2008) Microsomal Epoxide Hydrolase (EPHX1), Slow (Exon 3, 113His) and Fast (Exon 4, 139Arg) Alleles Confer Susceptibility to Squamous Cell Esophageal Cancer. Toxicology and Applied Pharmacology, 230, 247-251. http://dx.doi.org/10.1016/j.taap.2008.02.023

[28] Khedhaier, A., Hassen, E., Bouaouina, N., Gabbouj, S., Ahmed, S.B. and Chouchane, L. (2008) Implication of Xenobiotic Metabolizing Enzyme Gene (CYP2E1, CYP2C19, CYP2D6, mEH and NAT2) Polymorphisms in Breast Carcinoma. BMC Cancer, 8, 109. http://dx.doi.org/10.1186/1471-2407-8-109

[29] Srivastava, D.S., Mandhani, A. and Mittal, R.D. (2008) Genetic Polymorphisms of Cytochrome P450 CYP1A1 (*2A) and Microsomal Epoxide Hydrolase Gene, Interactions with Tobacco-Users, and Susceptibility to Bladder Cancer: A Study from North India. Archives of Toxicology, 82, 633-639. http://dx.doi.org/10.1007/s00204-007-0276-4

[30] To-Figueras, J., Gene, M., Gomez-Catalan, J., Pique, E., Borrego, N. and Corbella, J. (2001) Lung Cancer Susceptibility in Relation to Combined Polymorphisms of Microsomal Epoxide Hydrolase and Glutathione S-Transferase P1. Cancer Letters, 173, 155-162. http://dx.doi.org/10.1016/S0304-3835(01)00626-7

[31] Landi, S., Gemignani, F., Moreno, V., Gioia-Patricola, L., Chabrier, A., Guino, E., et al. (2005) A Comprehensive Analysis of Phase I and Phase II Metabolism Gene Polymorphisms and Risk of Colorectal Cancer. Pharmacogenetics and Genomics, 15, 535-546. http://dx.doi.org/10.1097/01.fpc.0000165904.48994.3d

[32] Zhou, W., Thurston, S.W., Liu, G., Xu, L.L., Miller, D.P., Wain, J.C., et al. (2001) The Interaction between Microsomal Epoxide Hydrolase Polymorphisms and Cumulative Cigarette Smoking in Different Histological Subtypes of Lung Cancer. Cancer Epidemiology, Biomarkers \& Prevention: A Publication of the American Association for Cancer Research, Cosponsored by the American Society of Preventive Oncology, 10, 461-466.

[33] Infante-Rivard, C., Krajinovic, M., Labuda, D. and Sinnett, D. (2002) Childhood Acute Lymphoblastic Leukemia Associated with Parental Alcohol Consumption and Polymorphisms of Carcinogen-Metabolizing Genes. Epidemiology, 13, 277-281. http://dx.doi.org/10.1097/00001648-200205000-00007 
Scientific Research Publishing (SCIRP) is one of the largest Open Access journal publishers. It is currently publishing more than 200 open access, online, peer-reviewed journals covering a wide range of academic disciplines. SCIRP serves the worldwide academic communities and contributes to the progress and application of science with its publication.

Other selected journals from SCIRP are listed as below. Submit your manuscript to us via either submit@scirp.org or Online Submission Portal.
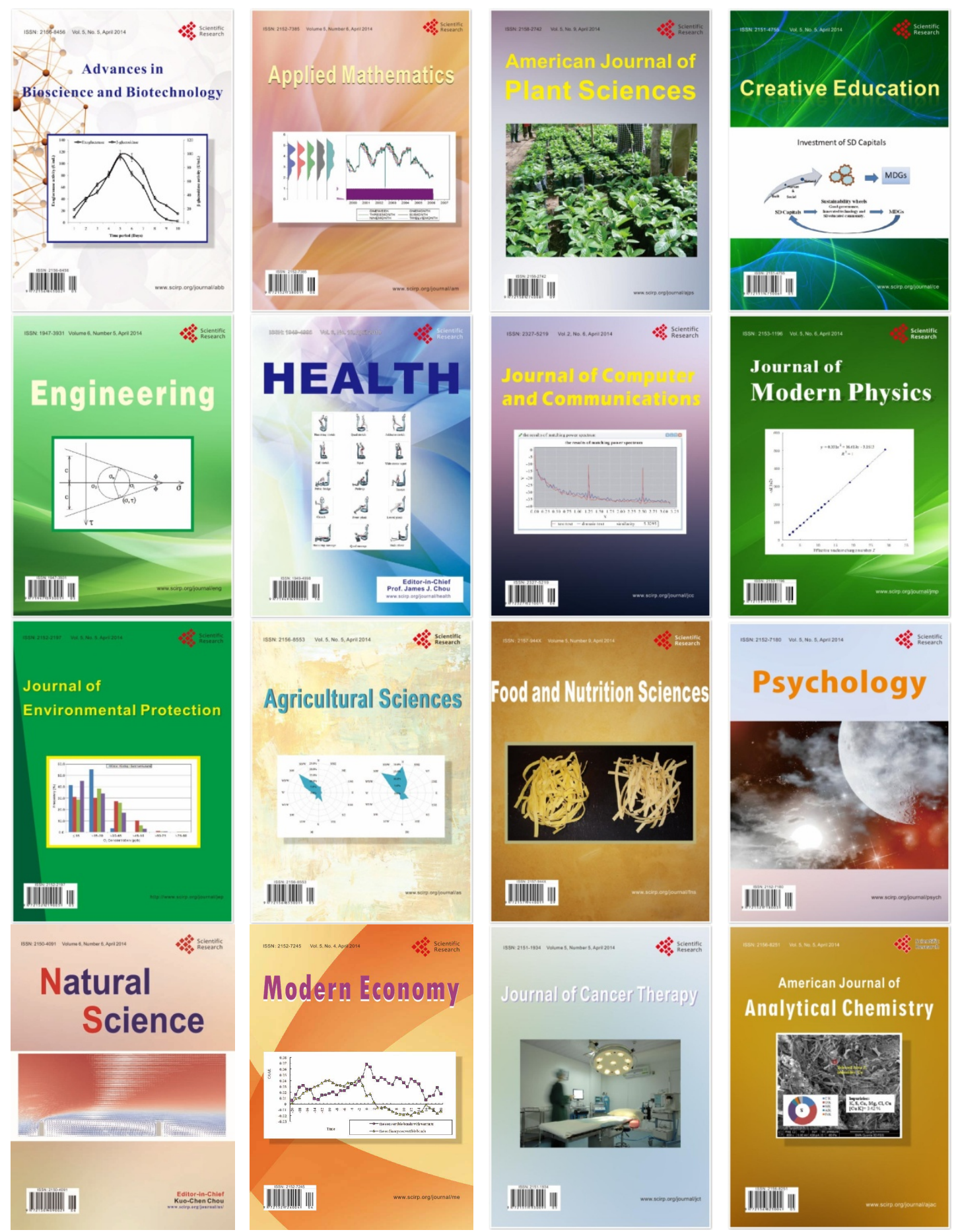